\title{
FAMILIAL INFANTILE COXA VARA
}

\author{
H. G. Almond, Liverpool, England
}

Case 1-A man of thirty-six sought advice because he had wrenched his left hip while cycling. He had had previous trouble with his hips from the age of eighteen, but the attacks of pain were infrequent and settled rapidly. He worked as a brewery manager with little difficulty. Four years before he attended he had had a piece of bone removed from the right knee for osteochondritis.

Figure 1 shows the radiographs of the hips. There was gross coxa vara, probably of the Fairbank or infantile type with superimposed osteoarthritic changes, more marked on the left side.

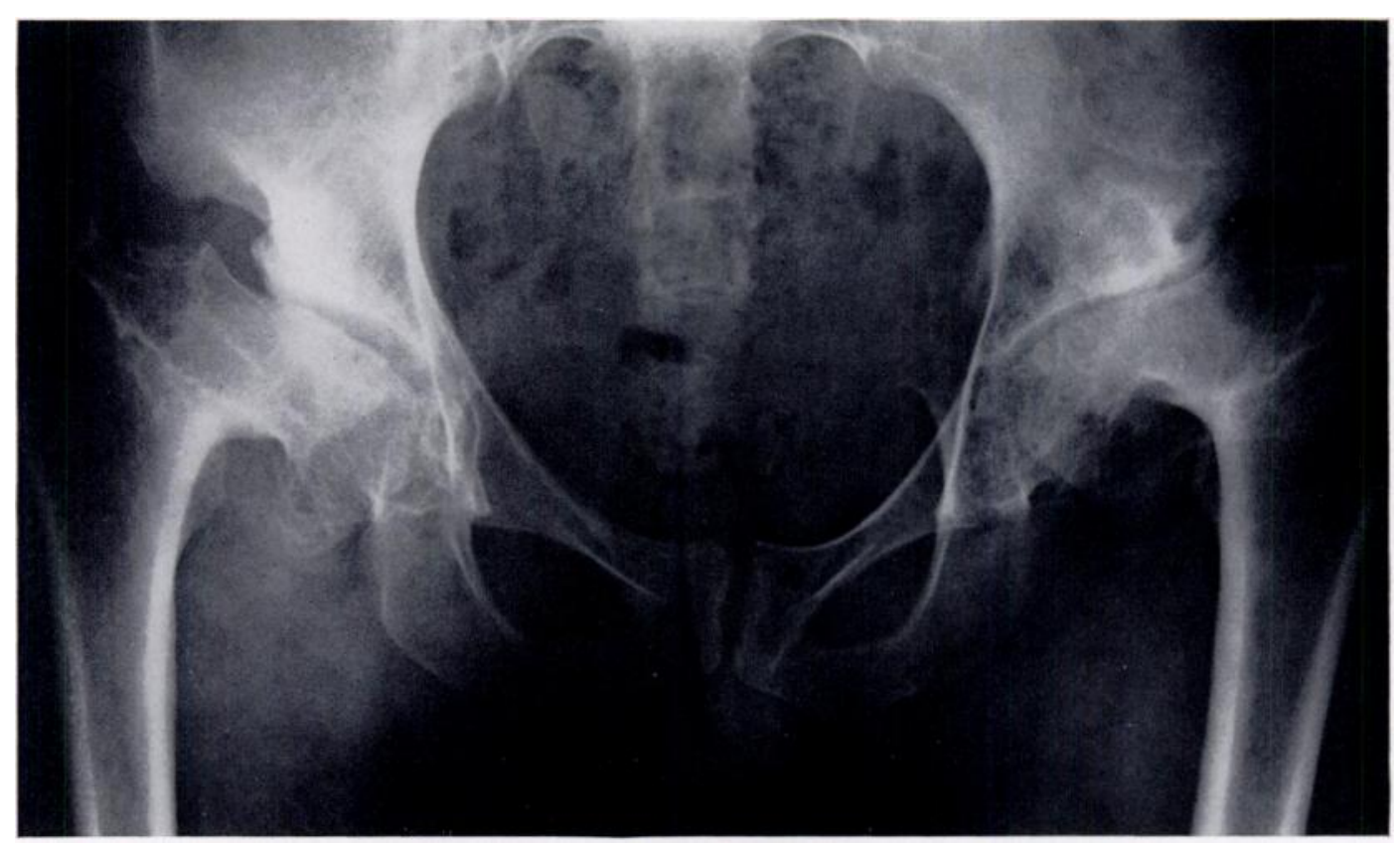

Fig. 1

Case 1.

The pain in the left hip caused by the wrench while getting on a bicycle disappeared with a week's rest and he was, he said, in his normal condition. There was about 30 degrees' flexion deformity and flexion to a right angle on both sides-the left a little better than the right.

When seen a year later the patient reported that he had had no further severe symptoms.

Case 2-At that time his first child, a girl, was five months old. I obtained his permission to have the child's hips radiographed, but the films at that time showed no evident abnormality (Fig. 2).

However, $I$ asked to see the child again in two years, and the radiographs taken then showed the typical triangular fragment with its base on the lower border of the femoral neck (Fig. 3). Figures 4 and 5 show the condition one and two years later. 


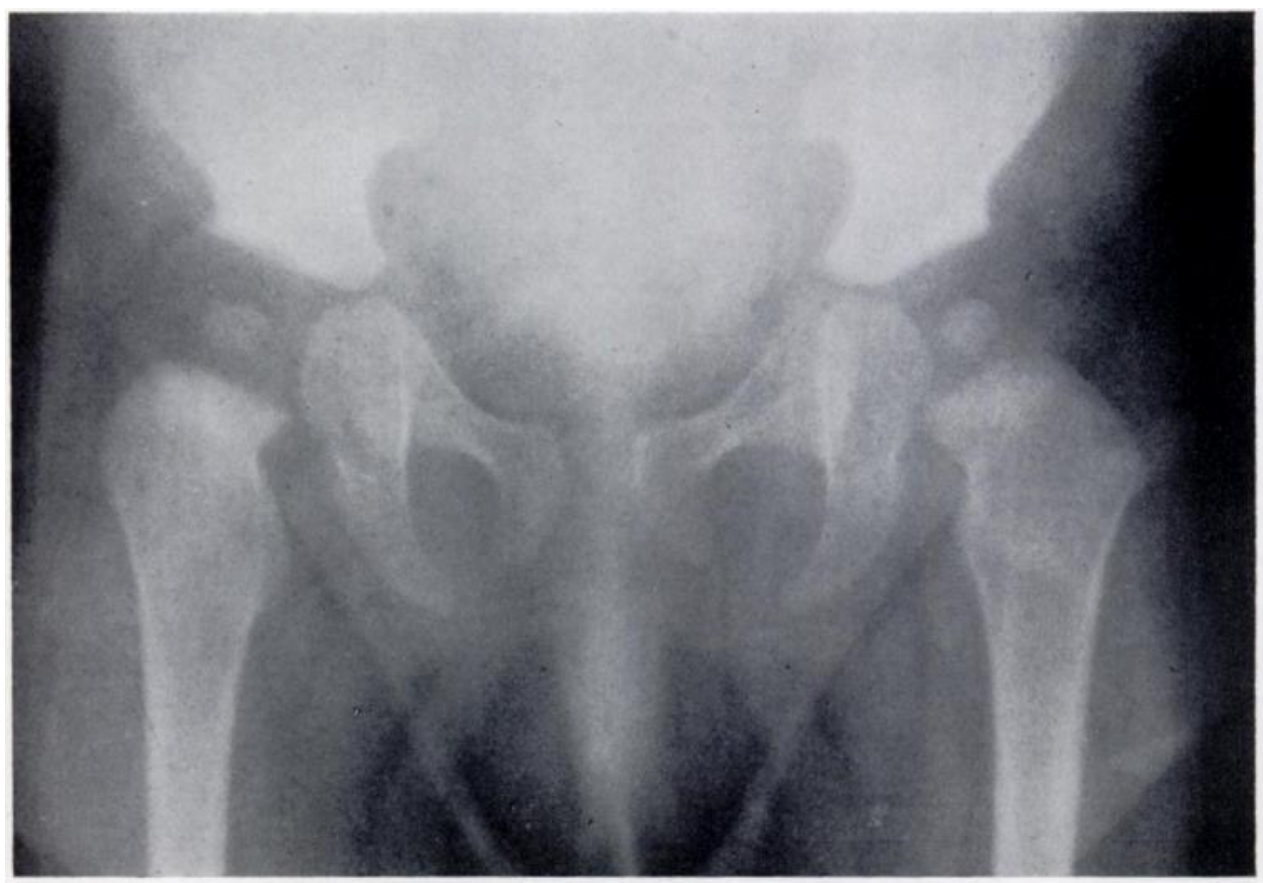

Fig. 2

Case 2-Initial radiograph.

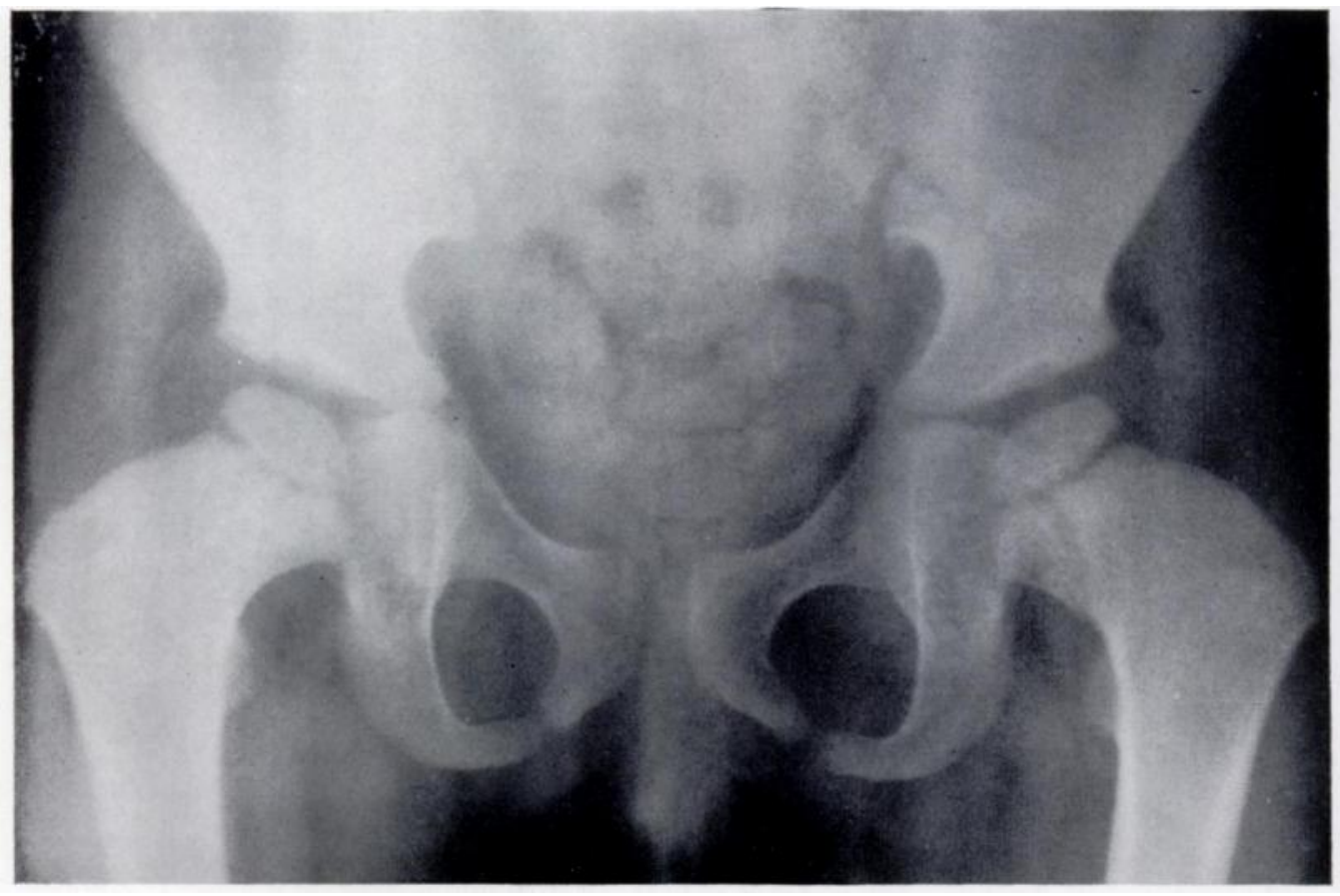

Fig. 3

Case 2-Two years later. 


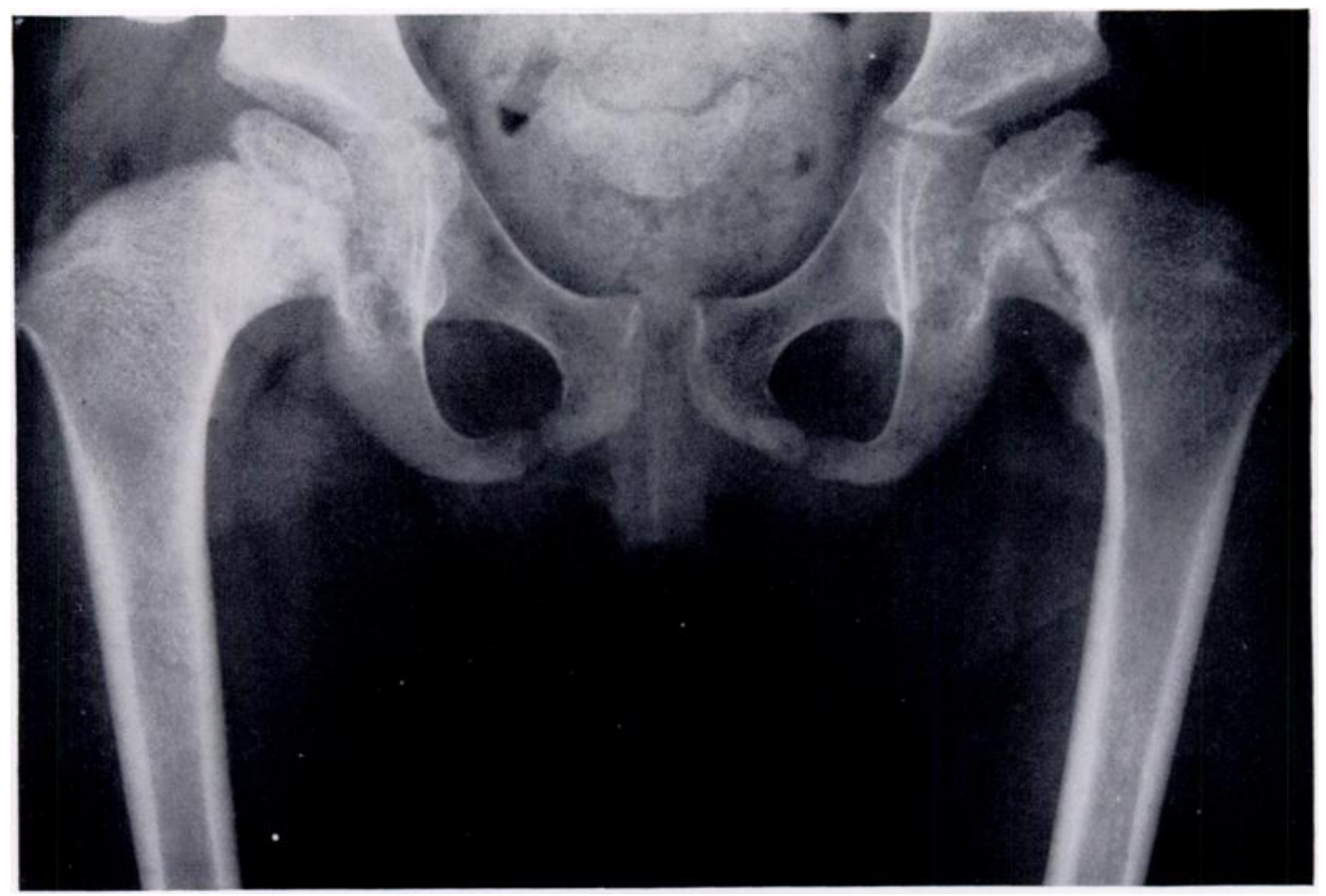

FIG. 4

Case 2-After three years.

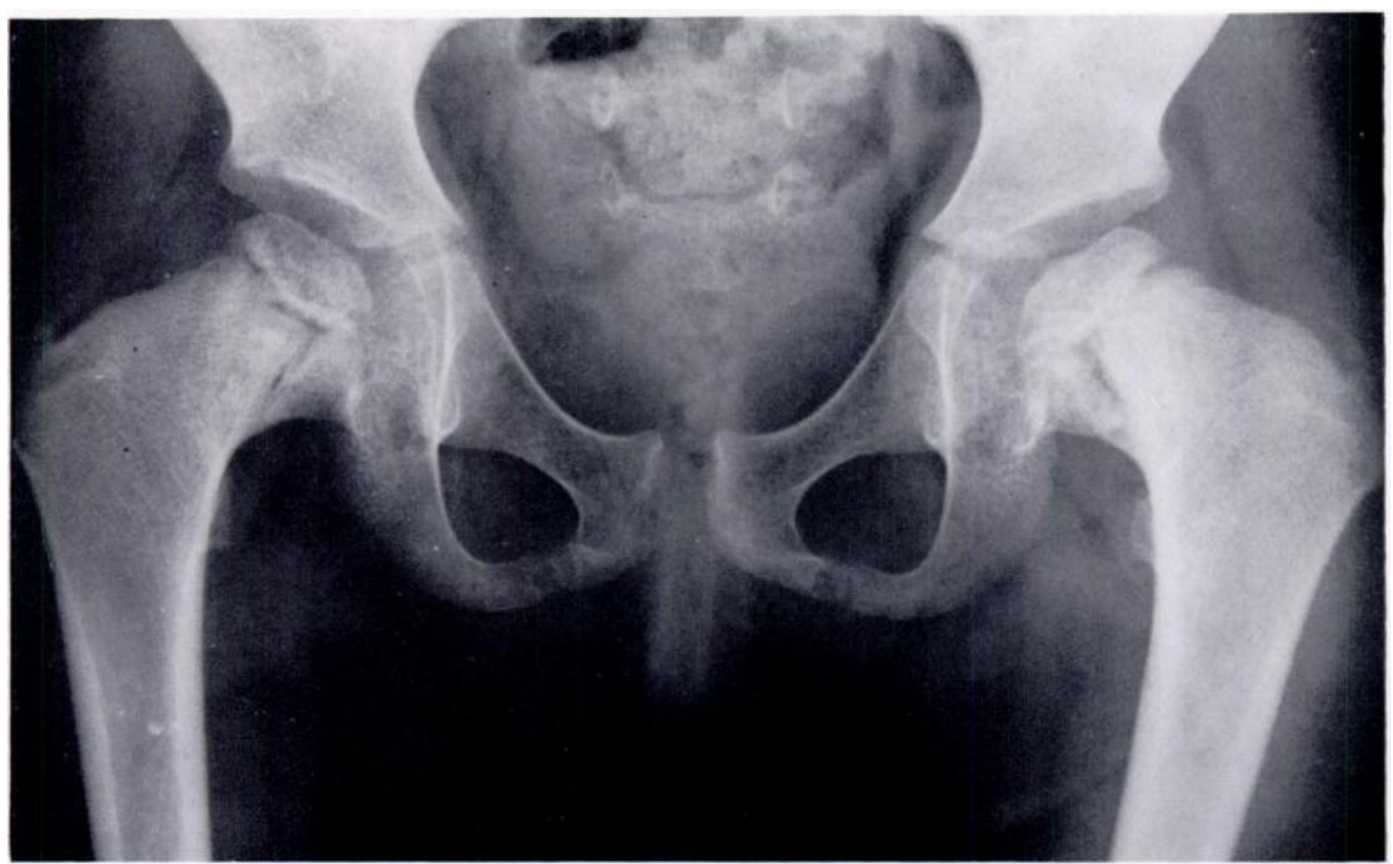

Fig. 5

Case 2-After four years.

VCL. 38 B, NO. 2, MAY 195 J́ 


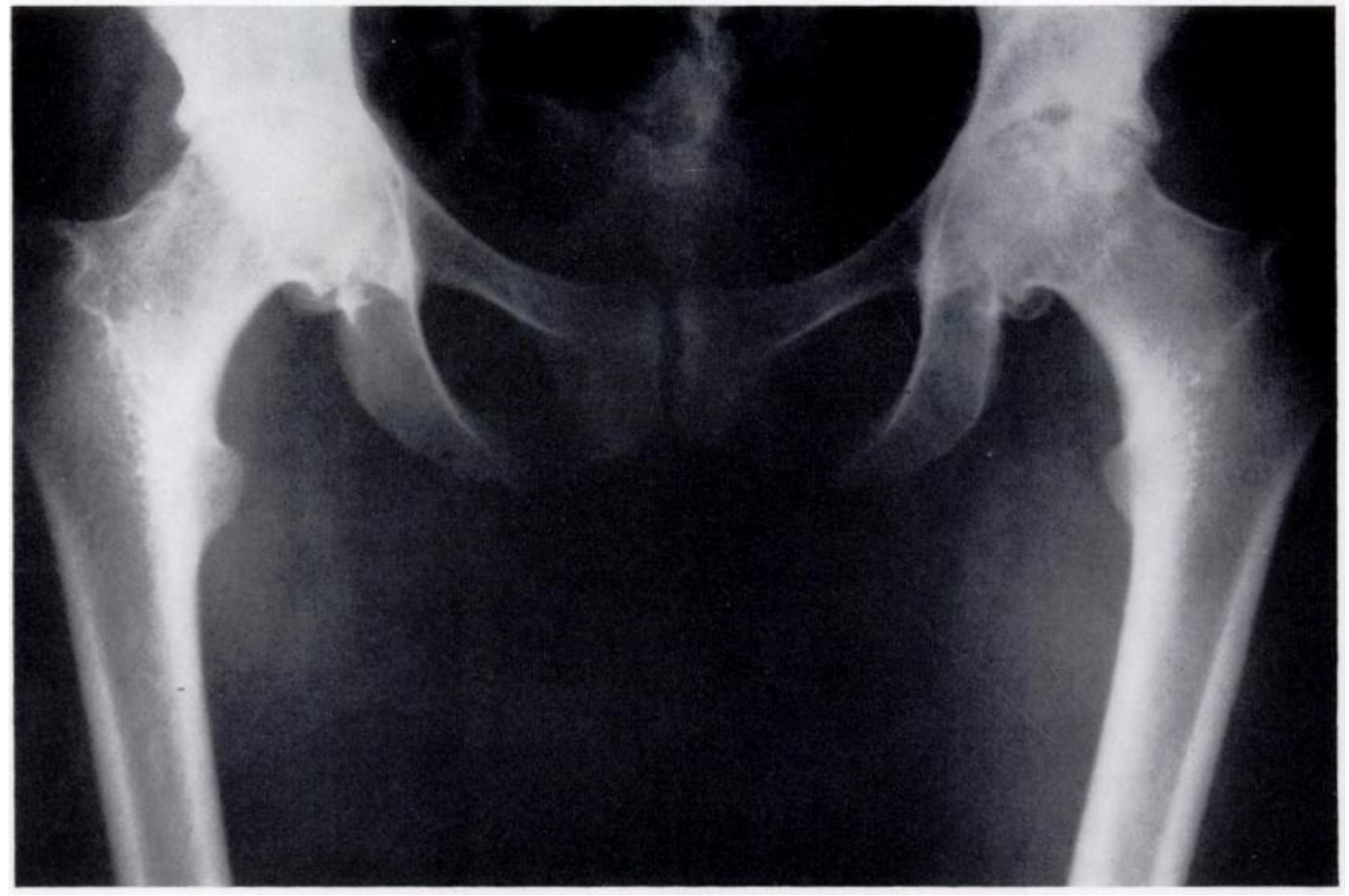

Fig. 6

Case 3.

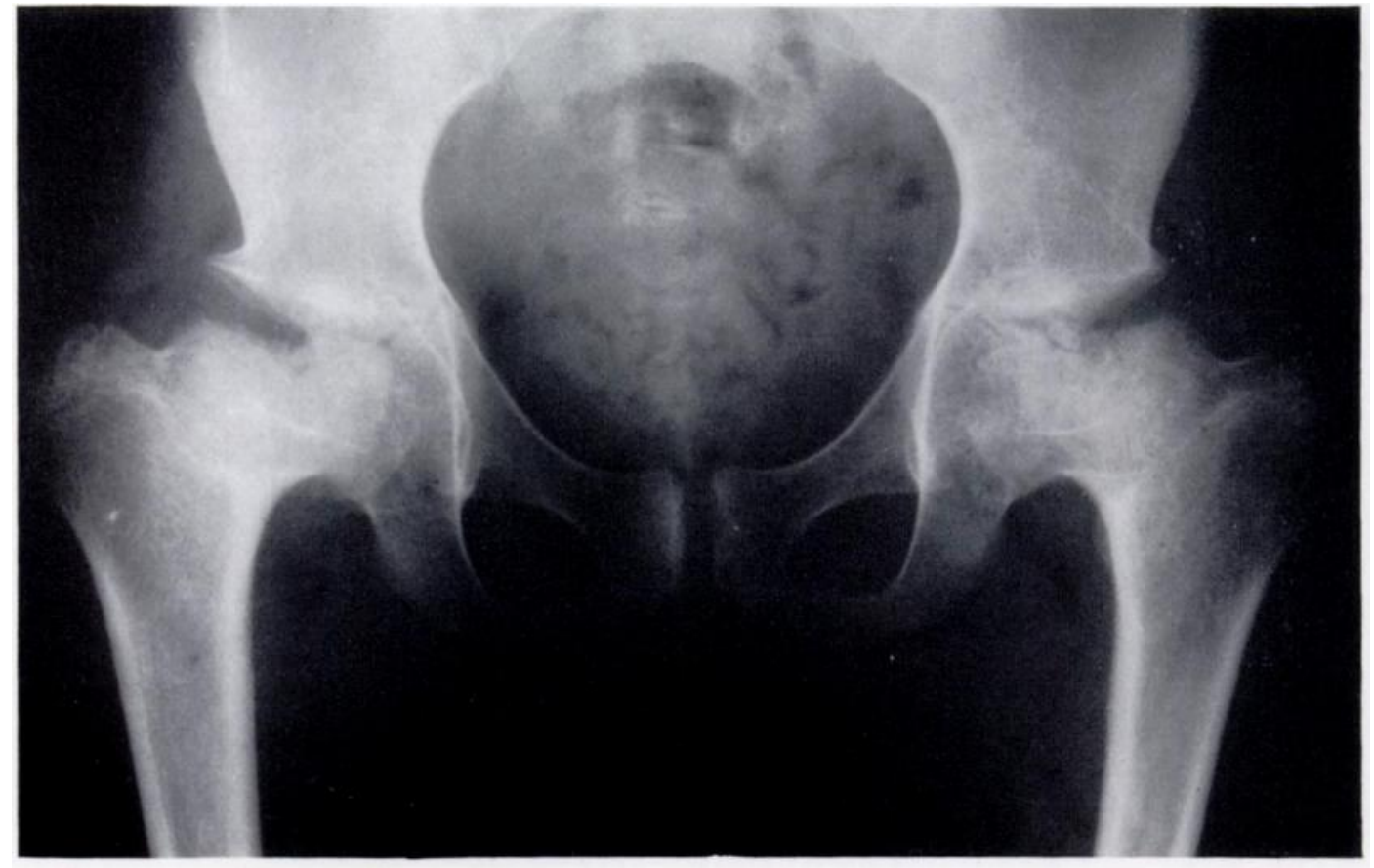

Fig. 7

Case 4

THE JOURNAL OF BONE AND JOINT SURGERY 
The abnormality is present in both hips, but no actual slipping has occurred, and in the latest radiograph (Fig. 5) the abnormal epiphysial line where it cuts the lower border of the femoral neck appears to be closing. The family tree is shown in Figure 8.

Case 3-The radiographs of the first patient's sister ( $\mathrm{Mr}$ Walton's patient) are shown in Figure 6. There is severe bilateral osteoarthritis of the hips at the age of thirty-two, but no coxa vara.

Case 4-The radiographs of this patient's daughter, however (Mr Law's patient), revealed a coxa vara of the type described by Fairbank, if not perhaps quite typical (Fig. 7).

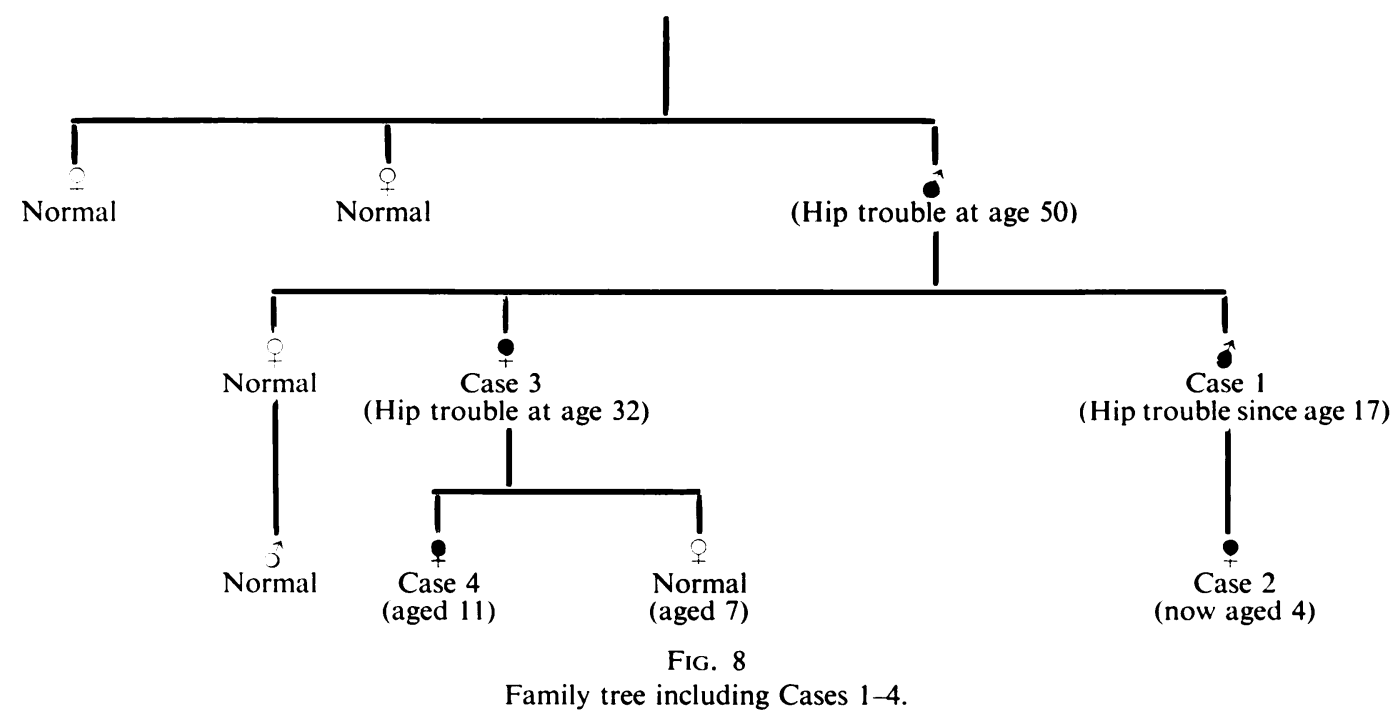

Comment-These cases bring out a number of interesting points. It is clear that infantile coxa vara is a familial condition, certainly in some cases. Two reviews of the condition (Babb, Ghormley and Chatterton 1949, Zadek 1935) failed to mention this fact. Indeed Babb et al. stated: "It suffices to say that no hereditary factor has been demonstrated." These authors suggested that a vascular disturbance in early life in the metaphysis might be responsible. In this series, however, the condition appears to be a true primary congenital defect. Jones and Lovett (1923) mentioned a case in mother and daughter, and Fairbank believed it to be a congenital lesion.

Another point shown in this series is that the condition is not necessarily the last phase of congenital short femur, as suggested by Golding (1939), though it can, of course, be associated with congenital short femur. In this case, ossification before the defect appeared in the neck was normal. It is clear also that infantile coxa vara does not necessarily cause slipping.

The supposition of most interest to me arises from the first patient's sister. She has severe bilateral osteoarthritis of the hips at the age of thirty-two, and she produced a child with infantile coxa vara. The mother must have had defective bone or cartilage structure of the femur to wear out her hips in thirty years or so and, moreover, it must have been a congenital defect of resilience. It is notable also that the first patient himself had an osteochondritis of the knee.

We are quite used to the idea of incongruous shape producing osteoarthritis as in Perthes' disease or subluxation, but it seems possible that a congenital defect of structure rather than shape might sometimes operate in the production of osteoarthritic change.

I would like to acknowledge my indebtedness to $\mathrm{Mr} \mathrm{W}$. A. Law and $\mathrm{Mr} \mathrm{L}$. H. F. Walton for allowing me to report their cases.

VOL. 38 B, NO. 2, MAY 1956 


\section{REFERENCES}

Babb, F. S., Ghormley, R. K., and Chatterton, C. C. (1949): Congenital Coxa Vara. Journal of Bone and Joint Surgery, 31-A, 115.

Barrington-Ward, L. E. (1912): Double Coxa Vara with other Deformities Occurring in Brother and Sister. Lancet, i, 157.

Fairbank, H. A. T. (1928): Infantile or Cervical Coxa Vara. In The Robert Jones Birthday Volume, p. 225. London: Humphrey Milford Oxford University Press.

Franke, G. (1912): Entstehungsursachen und Erkennung der Coxa Valga. München: R. Müller \& Steinicke. Golding, C. (1939): Congenital Coxa Vara and the Short Femur. Proceedings of the Royal Society of Medicine (Section of Orthopaedics), 32, 641.

JONES, R., and Lovetr, R. W. (1923): Orthopaedic Surgery. London: Henry Frowde, Hodder and Stoughton. Le Mesurier, A. B. (1948): Developmental Coxa Vara. Journal of Bone and Joint Surgery, 30-B, 595.

Le Mesurier, A. B. (1951): Developmental Coxa Vara (Correspondence). Journal of Bone and Joint Surgery, 33-B, 478.

Peabody, C. W. (1943): Subtrochanteric Osteotomy in Coxa Vara. Archives of Surgery, 46, 743.

ZADEK, I. (1935): Congenital Coxa Vara. Archives of Surgery, 30, 62. 